\title{
Uma pesquisa narrativa pelas experiências de professoras de línguas buscando viver histórias multilingues e decolonizadoras.
}

\author{
Cláudia Almeida Rodrigues Murta ${ }^{l}$ \\ Valeska Virgínia Soares Souza ${ }^{2}$ \\ Viviane Cabral Bengezen ${ }^{3}$
}

Resumo: Orientadas autobiograficamente, neste artigo, as autoras têm como objetivo explorar práticas docentes, sob uma perspectiva decolonial, a partir de propostas de ensino e de extensão na área de Linguística Aplicada. Elas socializam sua compreensão de práticas docentes decoloniais que considerem a importância do ouvir as diferentes vozes e de não marginalizar lugares geográficos e de fala aos quais não são atribuídos status no contexto contemporâneo de globalização e de relações de poder top-down. As propostas apresentadas para a análise vêm de três experiências vividas pelas pesquisadoras, ao ilustrarem um fazer docente que rompe com a valorização de decisões autoritárias e normalizadas no espaço escolar e acadêmico. O lugar como foco de tensões e possibilidades e os medos, dúvidas e incertezas nas paisagens do conhecimento de professores são os fios que perpassam as experiências vividas e que são discutidos. As autoras observam que suas experiências se distanciam de uma abordagem de ensino de línguas sistêmico e estrutural e abrem caminhos para se pensar quais práticas são necessárias para a valorização do local e quais parâmetros devem ser considerados na operacionalização de um currículo que honre o fazer docente decolonial, alinhado a uma formação antirracista e anti-opressiva de professores de línguas.

Palavras chave: Decolonização do ensino de línguas; Prática docente; Pesquisa Narrativa.

1 Doutorado em Estudos Linguísticos pela Universidade Federal de Uberlândia (UFU) em 2016Docente do Centro de Educação Profissional e do Programa de Mestrado Profissional em Letras da Universidade Federal do Triângulo Mineiro (UFTM).E-mail: claudia.murta@uftm.edu.br.

2 Doutorado em Estudos Linguísticos pela Universidade Federal de Minas Gerais (UFMG) em 2011. Docente no Instituto de Letras e Linguística (ILEEL) da Universidade Federal de Uberlândia (UFU). E-mail:valeskasouza@ufu.br.

3 Doutorado em Estudos Linguísticos pela Universidade Federal de Uberlândia (UFU) em 2017. Docente do Programa de Pós-Graduação em Estudos da Linguagem (PPGEL) da Universidade Federal de Goiás, Regional Catalão (UFG-RC). Email:vbengezen@gmail.com.

Gláuks: Revista de Letras e Artes-jan/jun. 2020 - Vol. 20, $N^{o} 1$ 


\section{Introdução}

Nós três, autoras e professoras de línguas, nos sentimos convidadas pelos proponentes do dossiê a buscar, em nossas próprias práticas docentes, experiências em que nos desafiamos a adotar uma postura decolonial e multilíngue e socializar essas experiências, com a esperança de que nossas narrativas possam colaborar para a área da Linguística Aplicada.

Nosso objetivo foi explorar práticas docentes que fazem parte de nossa luta por atitudes responsáveis e éticas de professores de línguas. Compartilhamos essa luta com docentes que, mesmo em situações de insegurança e de incerteza, demonstram o desejo de agir em prol da participação democrática, da inclusão e do respeito às diferenças. Contudo, é importante, antes de abordarmos o caminho teórico-metodológico trilhado, esclarecermos aos nossos leitores o que tomamos por decolonialidade, apresentando um panorama conciso acerca dos estudos decoloniais.

Constituído no final dos anos de 1990, formado por intelectuais latino-americanos, o Grupo Modernidade/Colonialidade (M/C), promoveu o chamado "giro" decolonial/ descolonial, constituindo-se em um coletivo que realizou um movimento epistemológico fundamental para a renovação crítica das ciências sociais na América Latina no século XXI. Uma espécie de radicalização do argumento pós-colonial que se refere à dissolução das estruturas de dominação e exploração configuradas pela colonialidade e ao desmantelamento de seus principais dispositivos.

Os estudos decoloniais, portanto, são formados por um conjunto heterogêneo de contribuições teóricas e investigativas sobre a colonialidade, "para compreender e atuar no mundo, marcado pela permanência da colonialidade global nos diferentes níveis da vida pessoal e coletiva" (BALLESTRIN, 2013). O propósito do paradigma decolonial é configurar outro espaço para a produção de conhecimento, uma forma distinta de pensamento, um outro paradigma, a possibilidade mesma de falar sobre mundos e conhecimentos de outro modo (ESCOBAR, 2003) contrário às grandes narrativas modernistas - o cristianismo, o liberalismo e o marxismo - uma possibilidade de pensamento não-eurocêntrico. O que os estudos decoloniais propõem é a "desobediência epistêmica", como defende Mignolo (2008), que se desvincule dos fundamentos genuínos dos conceitos ocidentais e da acumulação de conhecimento. 
De acordo com Mignolo (2008), a opção decolonial precisa "aprender a desaprender", ou seja, desprogramar nossos cérebros da razão imperial/colonial/moderna, cunhada numa identidade superior que subjuga as inferiores (raciais, nacionais, religiosas, sexuais, de gênero) categorizando-as como fora da esfera normativa do "real". De acordo com o autor, a retórica da modernidade foi a do progresso e bem estar para todos e em nome disso perpetuou a lógica colonialista de apropriação territorial e destruição de recursos naturais, a exploração do trabalho (diferentes formas de escravidão) e a dispensabilidade de vidas humanas (classificação racista).

Um dos construtos fundamentais do decolonialismo é a ideia de colonialidade do poder (BALLESTRINI, 2013), que prevê a continuidade da dominação mesmo com o fim do colonialismo. Esse termo foi ampliado mais tarde por Mignolo (2008) por se tratar de uma estrutura complexa, que imbrica outros níveis de atuação. Por isso, os autores Mignolo (2008) e Maldonado-Torres (2008) sugerem que a colonialidade se reproduz em uma tripla dimensão: a do poder, do saber e do ser. Três linhas principais de atuação do capitalismo mundial colonial/moderno se estabelecem desde o século XVI, que são a raça, o gênero e o trabalho. De acordo com o pensamento do grupo $\mathrm{M} / \mathrm{C}$, a raça e o racismo são os princípios organizadores que estruturam todas as múltiplas hierarquias do sistema-mundo (GROSFOGUEL, 2008 apud BALLESTRINI, 2013).

Nas palavras do autor, "às Américas chegou o homem heterossexual/ branco/ patriarcal/ cristão/ militar/ capitalista europeu", e é esse modelo que os decolonialistas querem contrapor, propondo outra forma de conceber o mundo, com a diversidade sociocultural própria da humanidade.

A partir desta breve contextualização teórica, que traçamos para entender a gênese do pensamento decolonial, passamos a apresentar o caminho teórico-metodológico que embasa nossa pesquisa, bem como expor pontos de aproximação entre as duas perspectivas filosóficas, a fim de justificar nossa intenção em nos posicionarmos em relação a estudos decoloniais.

\section{O caminho teórico-metodológico: a pesquisa narrativa}

A utilização de narrativas na pesquisa qualitativa começou quando, em diversas áreas do conhecimento, pesquisadores reconheceram o poder das histórias ao, por exemplo, tornar 
a relação médico-paciente mais efetiva ou potencializar as lutas de mulheres negras contra o patriarcado e o colonialismo (CLANDININ; ROSIEK, 2020). Para alguns pesquisadores, a pesquisa narrativa surgiu como uma resposta metodológica a paradigmas positivistas. Para nós, que seguimos a perspectiva de Clandinin e Connelly (2000:2015), a pesquisa narrativa é uma forma alternativa de pensar sobre a experiência vivida nas paisagens educacionais, continuamente colocando a ética relacional como fundamental durante o processo de investigação.

Assim como esses autores, nossa concepção de experiência parte da teoria deweyana, cuja ontologia da experiência é transacional, e não transcendental, ou seja, compreende a relação entre as atividades do sujeito e as consequências geradas. As experiências só podem ser entendidas no seu ciclo completo, por seus fatores internos e externos, não sendo meramente física nem mental. "Em uma experiência, coisas e eventos pertencentes ao mundo, físicos e sociais, são transformados através do contexto humano em que entram, enquanto a criatura viva é transformada e desenvolvida através de seu relacionamento com coisas antes externas a ela" (DEWEY, 1981, p. 251).

Além dessa característica transacional, a ontologia da experiência deweyana é temporal (compomos sentidos das experiências pensando narrativamente e considerando a história de vida das pessoas), contínua (as experiências não são fatos isolados que se conectam, mas se transformam e se conectam continuamente) e social (as experiências descritas sempre são em relação às interações com outras pessoas). As implicações epistemológicas dessa concepção de experiência podem ser notadas em relação ao ideal de pesquisa que buscamos - uma experiência que transforme a relação das pessoas com seus mundos e, dentro de um contínuo experiencial, gere novas relações que farão parte de experiências futuras. Ao situar a ontologia da experiência deweyana como a sustentação teórica da pesquisa narrativa, Clandinin e Rosiek (2020) nos ajudam a refletir sobre quais são os espaços fronteiriços entre essa perspectiva e outras três grandes correntes do pensamento filosófico: o pós-positivismo, o marxismo junto com a teoria crítica e o pós-estruturalismo, sobre os quais tratamos nos parágrafos seguintes.

Em relação ao pós-positivismo, enquanto a pesquisa narrativa parte de uma ontologia da experiência, as filosofias pós-positivistas começam com compromissos epistemológicos (partem de uma teoria) e tratam os compromissos ontológicos como considerações

4 In an experience, things and events belonging to the world, physical and social, are transformed through the human context they enter, while the live creature is changed and developed through its intercourse with things previously external to it. Essa e demais traduções são de responsabilidade das autoras. 
secundárias. Além disso, a concepção de realidade é diferente: pós-positivistas baseiam-se no realismo crítico, considerando a realidade independente das concepções que se tenha dela. A ideia fundamental de uma filosofia transcendental é, portanto, a de algo a priori, independente da ontologia da experiência. A pesquisa narrativa propõe-se a mais do que uma descrição da experiência - propõe intervenção, reconhecendo "que as descrições adicionam sentido à experiência, portanto mudando o conteúdo e a qualidade da experiência" (CLANDININ; ROSIEK, 2020, p. 235). Outra diferença importante entre a pesquisa narrativa e o póspositivismo é que, para os pesquisadores narrativos, "o fato de que a pesquisa está alterando os fenômenos sob estudo não é considerado um problema metodológico a ser superado. É o objetivo da pesquisa" " (p. 236, nossa tradução). Pensamos em qualquer descrição das experiências vividas como tentativas, mantendo viva a possibilidade de que a descrição pode alterar a qualidade da experiência descrita. Não buscamos uma essência, uma verdade, nem uma realidade fora daquela construída nas experiências vivenciadas durante a pesquisa.

A pesquisa narrativa está para a filosofia deweyana assim como a teoria crítica está para a filosofia marxista. O espaço fronteiriço entre essas duas correntes é permeado por um interesse de ambas em estudar como as instituições da nossa sociedade objetificam, segregam e anestesiam os indivíduos. Há também um interesse comum em ajudar as pessoas a resistirem aos sistemas de opressão, desenvolvendo um senso de agência e da realidade que as circula. Entretanto, as diferenças residem na concepção de realidade de cada uma. Clandinin e Rosiek (2020, p. 238) observam que, no marxismo, as análises consideram a organização social como conspiradora de destituição física de indivíduos e grupo e, ao mesmo tempo, epistêmica de pessoas do poder.

Em outras palavras, os sistemas de opressão nas sociedades capitalistas modernas incluem os meios pelos quais as fontes dessa opressão são obscurecidas. Esse processo de desviar a atenção das verdadeiras causas da opressão não é uma mera distração momentânea. Envolve, segundo os teóricos marxistas, desvios sustentados do pensamento, perpetrados pelas mais queridas e respeitadas tradições de nossas culturas: a religião, o nacionalismo e o humanismo liberal ${ }^{7}$.

5 descriptions add meaning to experience, thus changing the content and quality of the experience.

6 the fact that the inquiry is altering the phenomena under study is not regarded as a methodological problem to be overcome. It is the purpose of the research.

7 In other words, systems of oppression in modern capitalistic societies include the means by which the sources of that oppression are obscured. This process of deflecting atten- tion from the real causes of oppression is no mere momentary distraction. It involves, according to Marxist theorists, sustained deflections of thought perpe- trated by the most cherished and respected traditions of our cultures: religion, nationalism, and liberal humanism. 
As diferenças estão, portanto, nos detalhes dos compromissos ontológicos. A intervenção buscada pelo pesquisador narrativo tem como foco primeiro as qualidades da experiência vivida; é transformando as narrativas colaborativamente com as pessoas que viveram a experiência que a pesquisa narrativa busca estabelecer os fundamentos para uma mudança social. No marxismo, o homem é visto como um ser social; um representante de uma classe, enquanto na pesquisa narrativa, o homem é considerado em sua individualidade. Um dos alertas feito por Clandinin e Rosiek (2020, p. 241) em relação à teoria marxista é o seguinte:

\begin{abstract}
Ao descartar antecipadamente a experiência vivida das pessoas como uma possível fonte de conhecimento, ela simplesmente substitui uma fonte totalizante de autoridade externa - seja ela a igreja, o estado ou a ciência social pós-positivista - por outra. O resultado é o contínuo esvaziamento de poder exatamente daquelas pessoas que os estudiosos influenciados por Marx procuram emancipar. Esta destituição da experiência vivida é particularmente flagrante quando aplicada às comunidades que têm sido historicamente silenciadas por processos de colonialismo, patriarcado, homofobia e outras formas de opressão ${ }^{8}$.
\end{abstract}

Embora os detalhes dos compromissos ontológicos sejam diferentes, separando as correntes humanistas das socialistas, muitos pesquisadores narrativos têm mantido diálogos produtivos com colegas marxistas, somando benefícios às pesquisas e impactando a área para uma constante melhoria.

A terceira corrente de pensamento filosófico que tem sido parte da cartografia de fronteiras realizada por Clandinin e Rosiek (2020) é o pós-estruturalismo, que, frequentemente, é considerado o lar da pesquisa narrativa - uma vez que sua atenção recai sobre a estrutura linguística e narrativa do conhecimento. Entretanto, enquanto os pósestruturalistas ouviriam a narrativa de uma pessoa somente para identificar os discursos sociais que ali estão representados, pesquisadores narrativos partem de uma pragmática ontológica que trata a experiência vivida do início ao fim.

Os caminhos teórico-metodológicos da Pesquisa Narrativa e dos estudos decoloniais estão alinhados por diversas posturas dos pesquisadores que se filiam aos seus pressupostos. Esses pesquisadores são contrários a aceitar as grandes narrativas ou narrativas dominantes como verdades e buscam espaços outros ou formas alternativas para conceber o mundo e para

8 By preemptively dismissing the lived experience of persons as a possible source of insight, it simply replaces one totalizing source of external authority - be it church, state, or post-positivist social science-with another. The result is the continued disempowerment of exactly those persons the Marxist-influenced scholars seeks to emancipate. This dismissal of lived experience is particularly egregious when applied to communities who have been historically silenced by processes of colonialism, patriarchy, homophobia, and other forms of oppression. 
compreender as experiências. A esses pesquisadores interessa o acolhimento das subjetividades silenciadas, dos lugares marginalizados, da diversidade sociocultural própria da humanidade e do conhecimento prático pessoal construído na paisagem educacional a partir das experiências vividas. O trabalho de pesquisa desses pesquisadores é norteado pela ética relacional ao longo de todo o processo, desde a entrada em campo até a publicação do texto de pesquisa e para além da pesquisa (CLANDININ, 2013). Sintonizadas com as premissas apresentadas, descrevemos o desenho metodológico de nossa pesquisa na seção que se segue.

\section{A pesquisa narrativa autobiográfica e o contexto da pesquisa}

As participantes-pesquisadoras decidiram percorrer o caminho metodológico da pesquisa narrativa autobiográfica por acreditarem que a escrita de autobiografias colabora quando há intenção de se refletir de dentro do campo da experiência, não como observadoras externas da experiência. Para Freeman (2007, p. 120), “a autobiografia é o caminho por excelência para explorar as características dinâmicas - bem como os desafios profundos - da pesquisa narrativa, ou pelo menos a parte dela que considera o estudo abrangente das vidas

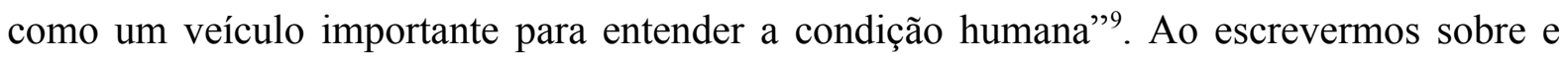
interpretarmos experiências passadas vividas as relacionamos com os interesses e as necessidades do presente, no intuito de nos transformarmos nesse processo.

Alguns questionamentos sobre relações de poder e validação do conhecimento vivenciadas em nossas práticas de docência e pesquisa nos levaram ao nosso puzzle de pesquisa $^{10}$, que foi estruturado a partir de reflexões sobre as hierarquias que permeiam as pesquisas e as práticas de ensino e aprendizagem na área da Linguística Aplicada. Seguindo o caminho teórico-metodológico da pesquisa narrativa, nós nos perguntamos como, em diferentes projetos de ensino e de extensão, nós experienciamos perspectivas críticas e/ou decoloniais de ensino de línguas, quem somos e quem estamos nos tornando nas paisagens

\footnotetext{
9 Autobiography is the inroad par excellence into exploring the dynamic features - as well as the profound challenges - of narrative inquiry, or at least that portion of it that looks to the comprehensive study of lives as an important vehicle for understanding the human condition.

10 Conforme Clandinin e Connelly (2015, p. 169), "pesquisadores narrativos são sempre constituidos em torno de uma curiosidade particular, o puzzle de sua pesquisa. Este é normalmente denominado problema de pesquisa ou questão de pesquisa. Entretanto, essa denominação de puzzle tende a representar equivocadamente o que acreditamos que seja o trabalho dos pesquisadores narrativos. Questões e problemas de pesquisa carregam consigo as qualidades da clara habilidade de definir e a expectativa das soluções, mas a pesquisa narrativa carrega muito mais um senso de busca, de um 're-buscar' ou um buscar novamente. A pesquisa narrativa relaciona-se mais com o senso de reformulação contínua em nossa investigação e isso está muito além de tentar apenas definir um problema e uma solução".
} 
educacionais onde vivemos essas experiências e quais são os fios narrativos que perpassam nossas narrativas.

Partimos do entendimento de uma escrita autobiográfica de histórias que nos constituem para redigir os textos de campo. As experiências são narradas por meio de histórias e compreendidas como contínuas, interativas e responsáveis por formar as histórias que nos constituem - concepção narrativa de identidade. Connelly e Clandinin (1999) explicam que o conceito de histórias que nos constituem (stories to live by) é o coração da compreensão narrativa de contexto e conhecimento, dão sentido e propósito para viver e moldam o modo como as pessoas sentem, pensam e agem. As histórias que nos constituem são quem somos e quem estamos nos tornando - uma visão de identidade que se desdobra ao longo do tempo, em diversos lugares e em interação com o meio que nos cerca, constantemente em construção.

O processo da pesquisa narrativa é de um continuum entre textos de campo redigidos a partir de notas de campo, diários reflexivos e documento escritos - e a composição de sentidos, que se materializa no texto final de pesquisa. Faz parte de nosso percurso de pesquisadoras escrever memórias de experiências significativas em nossas vidas no passado e no presente, e histórias que vivenciamos como professoras, orientadoras de pesquisas e coordenadoras de projetos de extensão. Essas notas de campo, diários reflexivos e documento redigidos nos contextos (ata, termo de compromisso) foram revisados para emoldurar as histórias mais importantes, em forma de textos de campo. Neste processo de composição dos textos de campo, nós nos engajamos na composição de sentidos dentro do espaço metafórico tridimensional da pesquisa narrativa, considerando a temporalidade, o lugar e a sociabilidade (CLANDININ, 2013).

Com atenção à justificativa de pesquisa, ao fenômeno sob estudo, ao método narrativo, à forma de interpretação e composição de sentidos, ao lugar da literatura teórica, a nosso posicionamento, ao tipo de texto que desejamos co-compor, à relação ética entre as pessoas, ao puzzle de pesquisa e à relevância social do estudo, iniciamos a transição dos textos de campo aos textos de pesquisa intermediários e ao texto de pesquisa, que é este artigo. Mantemos as perguntas constantemente em mente: para quem, por quê e o que estamos escrevendo? Quem são as personagens das narrativas que compartilhamos? Quais sentidos estamos compondo? Por que é importante falar sobre isso? É a partir das respostas a essas indagações que surgem durante a composição dos textos de campo, que modelamos o nosso texto de pesquisa. 


\section{Na busca por histórias de prática docente decolonial}

Nesta seção narramos algumas de nossas vivências pedagógicas em contextos de ensino de línguas que entendemos se alinharem ao pensamento decolonial. Essas experiências de ensino e de extensão foram vividas com estudantes de diferentes níveis de ensino, ensino fundamental, ensino técnico e ensino superior.

\section{Escrevendo a ata de uma assembleia: criatividade e trabalho colaborativo de alunos do ensino técnico}

A opção teórico-metodológica de ensino de língua materna da primeira autora deste texto pauta-se no trabalho com diferentes gêneros discursivos que se materializam nas práticas profissionais e na vida cotidiana dos alunos que cursam diferentes cursos técnicos em uma escola técnica vinculada a uma universidade federal. Para tanto, no planejamento das aulas de língua portuguesa aplicada à prática profissional, a professora elenca os gêneros que emergem mais comumente nas relações acadêmicas e profissionais de cada um dos cursos técnicos, sem contudo "engessar" o plano de ensino, tendo flexibilidade para ouvir e atender às necessidades dos alunos e também dos colegas professores, que vez ou outra, solicitam que trabalhe determinados textos com os alunos. Normalmente, em cursos técnicos, as disciplinas são estruturadas de forma compartimentada e instrumental, não deixando espaço para a criatividade, autonomia e reflexão por parte dos alunos, visto que a duração das disciplinas e de todo curso é muito reduzida. A experiência relatada diz respeito a uma prática que nasceu da necessidade dos alunos de transformarem sua realidade.

Os alunos de um dos cursos técnicos, em uma determinada aula, me relataram sobre sua insatisfação com o andamento das aulas até então, das práticas de ensino empregadas em algumas disciplinas, do relacionamento interpessoal entre professores e alunos, do isolamento e falta de comunicação da instituição com relação ao campus em que estudavam, e queriam saber a melhor forma de registrarem suas necessidades, como e a quem eles deveriam encaminhar esse registro. Eles enfatizaram que queriam um documento que formalizasse suas reivindicações e que não parecesse reclamação de "corredor" de alunos insatisfeitos.

Um dos alunos sugeriu que fizéssemos uma assembleia na qual todos manifestariam suas opiniões de maneira formal e minha sugestão para o registro escrito das discussões para encaminhamento seria uma ata.

Agendamos a assembleia e sugeri que os alunos anotassem previamente o que gostariam de manifestar, negociamos como seria o desenvolvimento da assembleia, seu objetivo, a ordem de pronunciamento, o assentimento da gravação da assembleia e o 
tempo. Os alunos elegeram uma colega para que fizesse o registro e a redação da ata e depois o texto seria socializado em uma plataforma de escrita colaborativa para a revisão de todos os participantes.

Texto de campo - reconstrução de memória de experiência vivida em 15/08/2018

A experiência vivenciada com os alunos, partindo de suas inquietações, de suas insatisfações, me fizeram refletir sobre a necessidade da construção compartilhada do currículo, sobre a prevalência da autoridade do professor na elaboração de conteúdos e escolhas metodológicas, da não participação do aluno nas decisões institucionais e principalmente no silenciamento de suas vozes. Ao tomarem a aula, insubordinando-se ao pré-estabelecido, para serem ouvidos formalmente, manifestando suas reivindicações, foi um ato de não aceitação a sua condição "subalterna" na hierarquia das instituições escolares. Esse posicionamento dos alunos me levou a refletir sobre a formação de professores que atuam no ensino técnico, sobre as práticas docentes ratificadas nas instituições, que alinhadas ao pensamento instrumental e mercadológico não dão espaço ao desenvolvimento da autonomia e da criatividade dos alunos para encontrarem o melhor caminho para sua formação.

\section{O exercício da (des)coberta: formação antirracista de professores de línguas}

O projeto de extensão que foi o contexto da experiência narrada nesta seção, desenvolvido entre 2018 e 2020, desenvolveu-se em parceria com quatro Instituições de Ensino Superior brasileiras e uma canadense. A história narrada neste artigo representa como a professora coordenadora do projeto vivenciou uma experiência em 2019:

Reservei o teatro para realizarmos o exercício da (des)coberta e fiz a divulgação. Os organizadores do evento me disseram que o espaço tinha capacidade para 300 pessoas.

- Quantas pessoas estão inscritas na oficina, professora?

- 30 - respondi.

- Ah, então tá tranquilo. O espaço será suficiente.

Porém, na hora de espalhar as cobertas, o espaço não foi suficiente. Todas as pessoas que participaram do exercício se posicionaram no palco. Os 300 lugares na plateia ficaram vazios.

Texto de campo - nota de campo da coordenadora do projeto, setembro de 2019.

A experiência vivida pela professora é uma oportunidade de iniciarmos reflexões acerca dos espaços que ocupamos nas paisagens educacionais onde vivemos, quais espaços são geralmente reservados a alunos e quais espaços são reservados para professores. A professora, coordenadora do projeto, achava importante que todas as pessoas que estavam inscritas na oficina, fossem elas estudantes ou palestrantes, ocupassem o palco. Essas pessoas 
representavam os povos indígenas antes da chegada do colonizador europeu, conforme a descrição da oficina apresentada nos parágrafos que se seguem.

O Exercício da (Des)Coberta é uma simulação da história da colonização do Canadá e começa com cobertas espalhadas no chão, representando as terras. As pessoas participantes pisam sobre as cobertas, desempenhando os papéis de indígenas que viviam em terras canadenses antes da chegada do colonizador. Há uma pessoa que narra e uma pessoa representando o branco colonizador, que seguem um roteiro com falas, leis, fatos, gestos, ações, música e dança, distribuem cartões, bonecas e pergaminhos que vão guiando todos os participantes pela história até os dias de hoje, de forma impactante.

Vivenciar essa experiência é uma oportunidade para discussão e reflexão sobre formação antirracista de professores de línguas, identidade dos professores em formação e dos educadores de professores e também sobre os impactos da colonização nas vidas de docentes e discentes, direcionando ações futuras para que os afetados componham novos sentidos de suas experiências vividas.

Ao final do exercício, poucas pessoas permanecem nas cobertas, que foram dobradas em pequenas partes e cobrem apenas uma fração de sua área original. Pela perda das terras e das crianças, além das mortes por doenças representadas no exercício, este pode deflagrar emoções e memórias difíceis. A cada exercício, as pessoas facilitadoras pensam em que tipo de apoio é possível fornecer durante a oficina e que tipo de acompanhamento pode ser disponibilizado. A coordenadora do projeto pensava constantemente em como encerrar a sessão de uma forma que as pessoas saíssem de uma maneira menos traumática. Por isso, estudantes envolvidos no projeto sempre davam uma explicação completa no início, sobre o que estava prestes a acontecer e diziam aos participantes que poderiam sair ou recuar se não se sentissem preparados para participar das partes do exercício que ressoassem com sua própria experiência. Ao final, sempre formavam uma roda para expressão do que desejassem.

\section{Por um contexto multilíngue, multicultural e de acolhimento além dos muros da universidade}

Concebido por uma das pesquisadoras, no intuito de contribuir para a consolidação do processo de internacionalização universitária, o projeto de extensão sobre o qual as experiências são narradas nesta subseção visa propiciar uma postura plurilíngue e de acolhimento da diversidade. Adolescentes de 11 a 14 anos, cursando as séries finais do 
Ensino Fundamental, têm a oportunidade de familiarização com as línguas espanhola, francesa e inglesa e aspectos culturais de países em que essas línguas são faladas. Constituise uma proposta que vai de encontro às tendências monolíngues de algumas comunidades e sociedades, podendo se tornar uma iniciativa relevante a ser considerada para a educação visando a internacionalização.

Tudo organizado para a inscrição dos estudantes interessados a participar no projeto de extensão. Hoje é o dia de receber estudantes e mães/pais/responsáveis para que entendam os objetivos do projeto e assinem conjuntamente o termo de compromisso, declarando ciência das responsabilidades requeridas para a permanência e conclusão:

1. Comparecer às aulas nos dias, horários e locais determinados, sendo imprescindível a participação em no mínimo $75 \%$ das aulas.

2. Justificar as ausências, quando acontecerem, à coordenação do projeto.

3. Dedicar-se às atividades propostas.

4. Respeitar e tratar bem colegas, ministrantes e convidados do projeto, bem como professores e técnicos administrativos da instituição.

5. Zelar pelo patrimônio da universidade, utilizando apropriadamente equipamentos e espaço físico.

As mães/pais/responsáveis chegam para a inscrição dos adolescentes e as dúvidas são muitas:

- Mas aí me filho pode escolher qual das três línguas vai aprender?, pergunta uma mãe.

- Não, a ideia é conhecer línguas e culturas diferentes. Durante as duas horas, são atribuídos 40 minutos para cada uma das línguas, explico.

- Então não tem aula só de inglês?, pergunta um pai.

Texto de campo - nota de campo da coordenadora do projeto, março de 2020.

Como lidar com as possíveis expectativas de que uma variante linguística ou que um aspecto cultural seja mais aceito que outros? Como fazer um desenho metodológico multilíngue, multicultural e de acolhimento? Enquanto idealizadora e coordenadora do projeto de extensão, estas questões me acompanharam desde o planejamento dos primeiros encontros em 2019.

Convidei estudantes internacionais de vários países como Costa do Marfim, Costa Rica, El Salvador, Espanha, Estados Unidos, Haiti, França e México que estavam fazendo mobilidade na universidade para falar sobre suas vidas, suas famílias e seus hábitos. A estudante da Costa do Marfim nos mostrou uma dança parecida com algumas danças brasileiras e o estudante do México trouxe um sombrero. Achei relevante também ter a participação de discentes e docentes que vivenciaram experiências em outros países: Canadá, Colômbia, França, México e Uruguai. A professora que viveu no Canadá trouxe vários panfletos de atrações para que os adolescentes pudessem ver e a aluna que morou na França fez um jogo de adivinhação. 
Aproveitei que os encontros presenciais aconteciam em laboratórios de informática, com diversos recursos didáticos tecnológicos digitais, e propus a exploração de sites da internet para que conhecessem aspectos culturais de diferentes países. Em uma das aulas, assistimos um vídeo em que estudantes mostraram objetos que ilustravam suas origens étnicas e, na aula seguinte, tivemos um momento em que os adolescentes mostraram objetos ilustrando a origem dos brasileiros. Eles trouxeram um arco, um berimbau, dentre outros objetos, para uma atividade de apresentação oral.

Um desafio foi propor um desenho pedagógico que oferecesse multilinguismo e multiculturalismo e, ao mesmo tempo, não tornasse a proposta confusa. No planejamento, com ajuda dos professores voluntários, articulei os temas trabalhados nas três línguas para que os estudantes pudessem perceber a relação entre os conhecimentos sendo construídos. Alguns dos temas trabalhados foram família, moradia, esportes, música, jogos, meio ambiente, reciclagem, vestuário, literatura, culinária, valores e projetos futuros.

Mesmo com a proposta de 40 minutos para cada língua seguindo temas em comum, notei que os adolescentes não se limitavam à língua sendo abordada naquele período. Ao nos reunirmos para as reuniões de planejamento, os professores voluntários e eu, conversamos sobre a importância de acolher essa mudança de código linguístico, já que isso nos dizia muito sobre a abertura dos adolescentes às diferentes línguas e a vontade de explorar toda a diversidade que estavam experienciando.

\section{Os fios que perpassam as experiências vivenciadas pelas três autoras}

Nós estruturamos nosso puzzle de pesquisa em torno das experiências que vivenciamos nas paisagens educacionais (universidade/escola/casa) onde trabalhamos, visitamos e moramos e as formas como essas experiências foram compostas por narrativas culturais, sociais, históricas, linguísticas e institucionais. Além disso, ao estruturar nosso puzzle de pesquisa, estamos atentas às possibilidades que nós, professoras, junto com estudantes, temos de re-historiar nossas experiências acadêmicas de forma a permitir a criação de espaços mais democráticos, multilíngues, multiculturais e para além dos muros das escolas e das universidades. Embora nossos estudos sejam separados, nós nos engajamos na 
pesquisa narrativa e, ao compor sentidos das experiências dentro do espaço metafórico tridimensional da pesquisa narrativa, podemos ver fios perpassando as experiências.

Tomando a narrativa como método e como fenômeno, além de termos um cuidado com a forma que escolhemos para expressar e divulgar os resultados - formas que valorizem a experiência vivida, a temática desta pesquisa foi sendo moldada e pudemos começar a entender a importância de criar espaços que nos permitam questionar as hierarquias das práticas nas paisagens do conhecimento dos professores de línguas, a importância de ter uma oportunidade de aprender quais são os receios, os medos e as angústias dos estudantes de cursos técnicos, das mães, dos pais e responsáveis pelos jovens no Brasil, dos alunos do curso de Letras, das/os docentes de línguas, de pesquisadores e da comunidade universitária como um todo.

\section{O lugar como foco de tensões e possibilidades}

Enquanto estávamos no campo de pesquisa, nos tornamos cada vez mais atentas ao papel que os lugares desempenham no desdobrar das experiências. Connelly e Clandinin (2006) sublinham a importância do lugar para pesquisadores narrativos e nos lembram que "todos eventos acontecem em algum lugar"11 (p. 480). Esse lugar está intrinsecamente relacionado às pessoas e experiências, pois somos moldados pelo lugar ao passo que o ocupamos e o moldamos. É importante entender que focalizar o lugar dentre os termos-chave de espaço tridimensional não significa que a temporalidade e a sociabilidade estão sendo desconsideradas, já que as três dimensões são indissociáveis.

A negociação dos diferentes sentidos de 'lugar' aconteceu no trabalho colaborativo da construção da ata, quando a professora trouxe para a frente da sala de aula (foco) uma inquietação que circulava entre as carteiras dos estudantes e, posteriormente, criou um espaço on-line de compartilhamento do texto. A professora mobilizou esse processo de mudança de espaços, não aceitando que fosse destinado a seus alunos um lugar 'subalterno', naturalizado na hierarquia das instituições escolares; ela exigiu que as vozes fossem ouvidas. Os alunos, por seu turno, não queriam que o documento fosse coisa de 'corredor' - um lugar de passagem, que leva a diferentes caminhos, mas que não é um lugar onde se habita, onde as 'falas' podem se perder no ar. Ao instituir um lugar para a escrita, para o registro, para a discussão e para a reescrita do texto, esse espaço fez com que as vozes dos alunos ganhassem 11 All events take place some place. 
forma, corpo, gênero para que ressoassem nas instâncias "superiores", para que se tornasse documento.

Ao se mover da plateia para o palco, o grupo do exercício da (des)coberta vivenciou diretamente a mudança de perspectiva e a quebra de hierarquia. Ao invés de ocuparem um lugar passivo, sentados em 30 das 300 cadeiras disponíveis na plateia, eles enfrentaram o espaço insuficiente do palco, lugar ativo e de protagonismo, das luzes da ribalta. Ao idealizar que os alunos saíssem do lugar reservado para eles (a plateia) e se posicionassem no lugar reservado para os professores (o palco) para o exercício da (des)coberta, a professora não previu que esse espaço não fosse o suficiente. Afinal, não deveria ser garantido um lugar de protagonismo? Talvez os participantes sentiram, mesmo antes de o exercício da (des)coberta começar, como é ter seu lugar não garantido, assim como os povos indígenas se sentiram. Ao praticarem o processo de perder progressivamente o seu lugar, na ação de dobrar a coberta e de se retirar do palco, provavelmente a relacionaram ao não acesso ao lugar de direito, comum no processo de colonização e na paisagem educacional.

O movimento de dentro para fora dos muros da universidade no projeto de extensão multilíngue, multicultural e de acolhimento mostra-se plural na percepção da coordenadora. O prestígio de ocupar o espaço da universidade passa a não restringir um público geralmente formado por adultos, mas agora também é o espaço de adolescentes. Alguns desses adolescentes vêm de escolas públicas que provavelmente não têm as facilidades tecnológicas digitais propiciadas pelo laboratório de informática, lugar onde são estimulados a interagir entre si e com o mundo, a partir dos visitantes e das pesquisas em sites da internet. O lugar de fala de prestígio também é uma das tensões vividas pela coordenadora no planejamento das ações, desde as menções ao inglês como sendo mais importante na fala de mães/pais/responsáveis às possíveis expectativas, de senso comum e presente em materiais didáticos amplamente disponibilizados, o que demanda intervenções ao longo da execução do projeto. Os lugares diferentes são mobilizados com a participação de estudantes internacionais vindos de países colonizados, como a estudante da Costa do Marfim e o estudante da Costa Rica.

As narrativas se entrecruzam pelo fio narrativo do lugar e nos fazem atentar para como nossas práticas docentes adotam uma postura decolonial. Em que medida mobilizamos os participantes de nossas aulas e de nossos projetos de um lugar periférico e marginalizado? Em que medida a geo-política (MIGNOLO, 2008) da paisagem educacional foi impactada em cada lugar das experiências? Acreditamos na relevância das iniciativas de ouvir as vozes de 
estudantes do curso técnico, de indígenas - a partir de relatos históricos - e de estudantes internacionais de países colonizados, vozes que tendem a ser silenciadas por identidades consideradas como superiores. A postura docente de explorar os lugares possíveis no intuito de subverter a naturalização dos lugares comuns, alguns reservados para os que têm mais prestígio e outros para os que têm menos prestígio, mostra-se um aspecto a ser valorizado na formação docente. Essa mobilização de lugares nos ensinou um fazer docente de descobertas sobre nós mesmas e sobre os contextos que habitamos, que modificamos e que nos modificam.

Dewey (1979, p. 43) escreveu que "as escolas precisam de mais oportunidades para atividades em conjunto, nas quais os educandos tomem parte, a fim de compreenderem o sentido social de suas próprias aptidões e dos materiais e recursos utilizados". O protagonismo que as iniciativas propiciaram aos participantes das três iniciativas de ensino e de extensão é outro aspecto a ser considerado na formação de professores, para uma prática docente crítica, decolonial e multilíngue. Com os estudantes do ensino técnico foi compartilhada a posição da professora, com os participantes do exercício da (des)coberta foi compartilhado o palco e com os adolescentes do projeto de extensão foi compartilhado o campus universitário. Nesses lugares, o papel de todos foi de participação e de centralidade do ser e do fazer, ampliando a oportunidade de entenderem seus desejos e suas ideias ao se moverem da margem para o centro da paisagem educacional.

\section{Medos, dúvidas e incertezas nas paisagens do conhecimento de professores de línguas}

"confesso que tive um pouco de receio de como os alunos se manifestariam, se haveria exaltação, desrespeito"

Texto de campo - diário reflexivo outubro de 2018

Embora a professora estivesse com receio de como os alunos se manifestariam, a assembleia aconteceu de forma organizada. Todos tiveram chance de falar e de ouvir e foi um momento único. Alguns alunos, cuja voz a professora nunca havia escutado, se posicionaram muito sabiamente. Outros, muito "tagarelas", escutaram com atenção os colegas. Cada um, de forma muito individual, mas pensando coletivamente, opinou, reivindicando melhorias para o curso, pensando em um currículo e em metodologias de ensino e aprendizagem que atendessem às necessidades dos alunos. A ata foi escrita com a ajuda do áudio e os temas 
discutidos foram sintetizados de forma que o documento não ficasse repetitivo e exaustivo. Todos tiveram oportunidade de revisar o texto, o que foi extremamente produtivo no conhecimento da língua e do gênero discursivo em análise.

Ao discutirmos sobre medo, ansiedade e incerteza, caminhamos rumo a um entendimento de que todas sentimos medo. Entretanto, nós três nos perguntamos o que nos faz seguir em frente, ter coragem e enfrentar os desafios, apesar do medo. Começamos a compreender mais profundamente o medo e a incerteza que sentimos quando fizemos um movimento retrospectivo em busca de alguns caminhos. Algumas pessoas, pesquisadoras, professoras, amigas ou parentes foram fundamentais para nos encorajar a seguir adiante. $\mathrm{O}$ fato de nós três trabalharmos juntas nesta pesquisa é um desses pontos de intersecção. Nós nos engajamos, nos ajudamos e nos fortalecemos. Há também formas de buscar apoio nas pesquisas, como na fala da anciã indígena Isabelle Kootenay, apresentada por Clandinin et al. (2018, p. 62):

Há uma roda da medicina na escola que eu fiz quando era vice-diretora. Havia muito racismo com as crianças. Eu não tenho medo de nada. Falo com as crianças que não é assim que vivemos juntos, por sermos preconceituosos. Não achamos que somos melhores por causa do nosso nome ou família ${ }^{12}$.

Assim como a Anciã Isabelle, outras pessoas vivem histórias de esperança e coragem, embora tenham vivido situações de opressão, violência ou desespero. Quando pensamos em nossas vidas e imaginamos quais os elementos que nos fazem superar o medo, concordamos que uma parte da coragem vem do entendimento de que nada está dado, portanto tudo está sendo construído. O conceito de histórias que nos constituem e o critério da continuidade da experiência deweyana, que coloca a compreensão de quem estamos nos tornando conectada a quem somos, junto com a natureza da pesquisa narrativa como de incerteza nos ajuda a elaborar sobre aquilo que nos move adiante.

Nos contextos dos projetos aqui apresentados, onde nos relacionamos com pessoas que vivem ou trabalham em contextos bilingues ou multilingues, criar espaços de discussão sobre medos, angústias e ansiedades pode impactar de forma favorável as pessoas envolvidas. Sua relevância social e acadêmica pode ser medida pelos impactos nas esferas pessoal, prática, social e acadêmica. Compreender como ocorreu a colonização, o genocídio cultural e a posse da terra no Canadá e no Brasil e quais são as implicações desses acontecimentos para

12 There is a medicine wheel in the school that I made when I was a vice principal. There was too much racism with the kids. I don't fear anything. I talk to the kids that this is not the way we live together, by being prejudiced. We don't think we are better because of our name or family. 
a educação e para a vida das pessoas nesses países, por exemplo, além de aprender com autoras e autores, escritoras negras (GONZALEZ, 1983; EVARISTO, 2016), escritores indígenas (POTIGUARA, 2019; MUNDURUKU, 2001) professores, pensadores indígenas (WERÁ, 2018, 2019; KRENAK, 2019), ao entender as origens dos povos, as formas de reconciliação entre eles e as relações de poder que permeiam as sociedades, podemos iniciar transformações, considerando nossa própria responsabilidade e posicionamento no mundo, caminhando em direção a ações futuras para diminuir as injustiças, ou seja, combater a herança de desigualdades e injustiças herdadas do passado que têm sido continuamente reproduzidas no presente.

Além disso, há um estreitamento dos laços entre nós e as instituições participantes dos projetos, trocas de experiências inter e transdisciplinares com alunos e professores da educação básica e das comunidades quilombolas e a criação dessa rede de pessoas interessadas em compreender as experiências em contextos bilingues e multilingues e encaminhamentos futuros.

\section{Considerações finais}

No início desta jornada de compreender narrativamente as hierarquias que permeiam as pesquisas e as práticas de ensino e aprendizagem de línguas na área da Linguística Aplicada, tendo como foco nossas próprias experiências em projetos de ensino e de extensão, nós co-compusemos narrativas de práticas decoloniais de ensino de línguas. Fundamentadas em uma ontologia da experiência deweyana e com cuidado à ética relacional da pesquisa narrativa, compusemos sentidos para as experiências vividas e construímos histórias em torno dos temas do lugar, do medo, da incerteza, da coragem e da esperança, que foram fios perpassando as histórias elencadas para serem discutidas neste artigo.

Professores e formadores de professores que atuam em contextos bilíngues ou multilíngues podem aprender, com as narrativas aqui desdobradas e até certo ponto desempacotadas (considerando o limite de páginas de um artigo científico), sobre como os lugares topológicos onde vivemos e a disposição das pessoas nesses espaços podem impactar a forma como as hierarquias são mantidas ou chacoalhadas e, ainda que timidamente, transformadas. 
Interconectadas com as questões de lugar, compusemos sentido, também, das experiências das professoras lidando com o medo, a insegurança e a incerteza. Concluímos que essas emoções afloram mais fortemente quando criamos alguma expectativa de que haveria um certo, normal, ideal, verdadeiro e passível de ser atingido e quando nos consideramos incapazes e ansiosas em comparação ao outro. Porém, ao prestarmos atenção aos fios que entrecruzaram nossas experiências, aprendemos que ao pensarmos no coletivo, no trabalho colaborativo, na inversão ou exclusão de hierarquias, nós sacudimos as bases nas quais a Linguística Aplicada se fundou e, questionando modelos até então considerados ideais, transformamos nossa forma de nos posicionarmos no mundo e a relação com as pessoas que estão à nossa volta.

Fazendo um movimento prospectivo, projetamos infinitas possibilidades para as práticas decoloniais em contextos bilíngues ou multilíngues, imbuídas da certeza da incerteza e da coragem para romper com ideais que oprimem e excluem qualquer pessoa que não se adeque a um mundo dominado pelas grandes corporações e pelos interesses de um espectro nomeado economia. Quando começarmos a nos unir como comunidade e a valorizar e validar experiências humanizadoras, iremos continuamente desconstruir verdades e caminhar rumo a uma co-construção de experiências emancipadoras.

\section{Referências Bibliográficas}

BALLESTRIN, L. América Latina e o giro decolonial. Revista Brasileira de Ciência Política, v.2, n.11, p.89-117, 2013.

CAINE, V.; ESTEFAN, A.; CLANDININ, D. J. A return to methodological commitment reflection on narrative inquiry. Journal of Educational Research, v. 57, n. 6, p. 574-586, 2013.

CLANDININ, D. J. 2013. Engaging in narrative inquiry. New York: Routledge, 2013. 232 p.

CLANDININ, J. D. et al. The Relational Ethics of Narrative Inquiry. Routledge, 2018.

CLANDININ, D. J.; CONNELLY, M. Narrative Inquiry: Experience and Story in Qualitative Research. San Francisco: Jossey Bass, 2000. 211 p.

CLANDININ, D. J.; CONNELY, M. Pesquisa Narrativa: experiência e história em pesquisa qualitativa. 2 ed. rev. Tradução: GPNEP: Grupo de pesquisa narrativa e educação de professores. ILEEL/UFU. Uberlândia: EDUFU, 2015. 
CONNELLY, F. M.; CLANDININ, D. J. Shaping a professional identity: Stories of educational practice. New York, NY: Teachers College Press, 1999.

CONNELLY, F. M.; CLANDININ, D. Jean. Narrative Inquiry. In: GREEN, J.; CAMILLI, G.; ELMORE, P. (Eds). Handbook of Complementary Methods in Education Research. 2006. p. 375-385.

CLANDININ, D. J.; ROSIEK, J. Mapping a Landscape of Narrative Inquiry Borderland Spaces and Tensions. In: CLANDININ, D. J. Journeys in Narrative Inquiry: The Selected Works of D. Jean Clandinin. New York: Routledge, 2020, 334 p.

DEWEY, J. Democracia e educação: introdução à fillosofia da educação. Tradução de Godofredo Rangel e Anísio Teixeira. 4 ed. São Paulo: Companhia Editora Nacional, 1979.

DEWEY, J. The later works, 1925-1953: Vol. 10. Art as experience (J. A. Boydston, Ed.). Carbondale, IL: Southern Illinois University Press, 1981.

ESCOBAR, A. Mundos y conhecimientos de outro mundo - O programa de investigación de modernidade/colonialidad latinoamericano. Revista Tabula Rasa, n.4, p. 50-161, 2003.

EVARISTO, C. Olhos d'água. Pallas Editora, 2016.

FREEMAN, M. Autobiographical understanding and narrative inquiry. In: CLANDININ, J. D. (Ed.). Handbook of narrative inquiry: mapping a methodology. Thousand Oaks; London; New Delhi: Sage/University of Alberta, 2007. p. 120-145.

GONZALEZ, L. Racismo e sexismo na cultura Brasileña. In: SILVA, L. A. Movimentos sociais urbanos, minorías étnicas e outros estudos. ANPOCS. Brasilia, 1983.

GROSFOGUEL, R. Para descolonizar os estudos de economia política e os estudos póscoloniais: transmodernidade, pensamento de fronteira e colonialidade global. Revista Crítica de Ciências Sociais, n. 80, p. 115-147, 2008.

KRENAK, A. Ideias para adiar o fim do mundo. Editora Companhia das Letras, 2019.

MALDONADO-TORRES, N. La descolonización y el giro des-colonial. Revista Tábula Rasa, v.2, n.9, p. 61-72, 2008.

MIGNOLO, W. Desobediência epistêmica: a opção descolonial e o significado de identidade em política. Cadernos de Letras da UFF, Dossiê: literatura, língua e identidade, n.34, p.287-324, 2008.

MUNDURUKU, D. Meu vô Apolinário: um mergulho no rio da (minha) memória. Studio Nobel, 2001.

POTIGUARA, E. Metade cara, metade máscara. São Paulo: Global, 2019.

WERÁ, K. (Org.). Biraci Yawanawá. Rio de Janeiro: Beco do Azougue Editorial Ltda., 2018.

Gláuks: Revista de Letras e Artes-jan/jun. 2020 - Vol. 20, $N^{o} 1$ 
WERÁ, K. (Org.). Sônia Guajajara. Rio de Janeiro: Beco do Azougue Editorial Ltda., 2019.

\title{
A narrative inquiry into the experiences of female language teachers seeking to live multilingual decolonizing stories
}

\begin{abstract}
This is an autobiographically oriented article in which the authors aim to explore teaching practices, from a decolonial perspective, from teaching and community outreach proposals in the realm of Applied Linguistics. They socialize their understanding of decolonial teaching practices that consider the importance of listening to different voices and not marginalizing geographic and speech places that are not given status in the contemporary context of globalization and top-down power relations. The proposals presented for the analysis come from three experiences lived by the researchers, which illustrate teaching practices that break with the valorisation of authoritarian and normalized decisions in the educational space. The place as the focus of tensions and possibilities and the fears, doubts and uncertainties in the landscapes of teachers' knowledge are the threads that permeate the lived experiences which are discussed. The authors note that their experiences distance themselves from a systemic and structural language teaching approach and open ways to think which practices are necessary for the valorisation of the place and which parameters must be considered in the operationalization of a curriculum that honours the decolonial teaching, aligned with an anti-racist and anti-oppressive language teacher education .
\end{abstract}

Keywords: Decolonization of language teaching; Teaching practice; Narrative Inquiry. 